\title{
INTERCULTURALIDADE NA EDUCAÇÃO INFANTIL: A MATRIZ CURRICULAR DAS RELAÇÕES ÉTNICO- RACIAIS.
}

Regina Lucia Fernandes Albuquerque ${ }^{1}$

\section{INTRODUÇÃO.}

A pesquisa ocorreu no ano letivo de 2017, em uma turma de Educação Infantil, com alunos na faixa etária de cinco anos, em uma escola da rede Municipal de Educação do Rio de Janeiro, localizada na Zona Norte desse município. Tem por objetivo analisar práticas intraescolares nas interações cotidianas da turma acompanhada que se aproximem de uma concepção curricular intercultural quanto às relações étnico-raciais. Para tanto, utiliza a opção metodológica de pesquisa no/do/com o cotidiano (FERRAÇO, 2007; OLIVEIRA, 2008), compreendendo o cotidiano como campo de produção de conhecimentos nas relações nele (por ele e com ele) desenroladas. As atividades analisadas ocorreram entre os meses de maio a dezembro de 2017 e foram divididas em três grupamentos: rodas de leitura, atividades entre pares e atividades integradas com responsáveis de alunos.

Práticas intraescolares que se aproximem de um currículo multicultural ${ }^{2}$ vêm sendo fomentadas por políticas públicas no campo da educação. Em específico em relação às questões da educação para as relações étnico-raciais, vigora nacionalmente a lei 11.645/2008 que institui a obrigatoriedade do Ensino de História e Cultura Africana e Afrobrasileira e de etnias indígenas na Educação Básica, substituindo a redação do artigo 26A da lei 9394/96, a partir da implementação da lei $13.415 / 2017 .^{3}$

11

Doutoranda Programa de Pós graduação em Educação, Conhecimento e Inclusão Social (PPGE- UFMG)

${ }^{2}$ Considerando a polissemia que abarca o termo multiculturalismo e sua diversidade de usos, incluindo sua apropriação por linhas epistemológicas conflitantes (CANEN e OLIVEIRA, 2002), optou-se por usar o termo multiculturalismo em relação às políticas públicas citadas por considerá-lo genericamente mais abrangente. A perspectiva intercultural (CANDAU, 2008) na qual o estudo se situa será melhor abordada adiante.

${ }^{3}$ A Lei 13.415/2017 traz alterações a Lei 9.394/96, mantendo a redação do artigo 26-A em consonância com a Lei 11.645/2008, substituindo a redação deste artigo que vigorava com texto da Lei 10.639/2003. 
Nas interações entre pares na turma acompanhada foi possível perceber falas que reproduziram estereótipos a determinados grupos sociais, circunscrevendo-os em um lugar de produção de estigmas. Por exemplo: expressões como "cabelo duro" foram recorrentemente utilizadas para caracterizar alunas com cabelo crespo; a utilização do termo preto/preta como xingamento ("Tia, o João me chamou de preta.") 4; hipóteses das crianças sobre a origem de sua cor e o desejo de modificá-la (“Tia, o Igor é preto porque ele só toma Nescau. Eu bebo vitamina. Eu vou ficar clarinha."). Essas falas apontam para um referencial de perfil estético construído a partir da branquitude, valorizando os traços físicos fenotipicamente brancos.

A construção de um currículo intercultural se orienta por práticas intraescolares que não apenas abarcam a diferença, mas que partem da e na diferença como instrumento de construção de pedagogias e de olhares contra hegemônicos sobre o currículo, compreendendo a construção da diferença como prática social (CANEN; OLIVEIRA, 2002). Dessa maneira, se faz necessária a construção de práticas intraescolares que apresentem temáticas identitárias inseridas em uma agenda político-social, compreendendo o currículo não apenas como uma ferramenta técnica, mas como um campo de produções que articula saberes para materialização de práticas socialmente referenciadas a partir de marcadores de classe, pertencimento de gênero, raça e etnia.

Essa proposta relaciona-se com os eixos norteadores das Diretrizes Curriculares Nacionais de Educação Infantil (1998), que se reportam aos princípios éticos da autonomia, da responsabilidade, da solidariedade, aos princípios políticos dos direitos e deveres de cidadania, do exercício da criticidade e do respeito à ordem democrática e aos princípios estéticos da sensibilidade e da diversidade de manifestações artísticas e culturais (DCNEI, 1998).

Ainda que exista o marco legal de garantia de acesso na Educação Básica à educação para as relações étnico-raciais, esta ainda vigora de maneira precária no interior das instituições escolares. No caso da escola acompanhada a dificuldade para desenvolvimento da matriz curricular da educação para as relações étnico raciais é manifesta pela postura da gestão escolar que organiza o currículo da Educação Infantil a partir de marcos temporais de datas comemorativas. As Diretrizes Curriculares Nacionais para a Educação das Relações Étnico Raciais e para o Ensino de História e Cultura Afro Brasileira e Africana (2004) explicita que o ensino dessa matriz curricular deve ser tratado de forma transversal, ao longo do período do ano letivo, não se configurando como um exercício pontual de abordagem da temática. Dessa maneira, é possível identificar uma contradição entre as diretrizes curriculares nacionais com a concepção curricular adotada pela escola. Ainda assim, a realização do projeto com os alunos na/da/com a turma de Educação Infantil ocorreu de maio até dezembro do ano

${ }^{4}$ Os nomes de estudantes utilizados são fictícios considerando a preservação da identidade dos educandos. 
letivo de 2017. A seguir, apresenta-se a revisão de literatura que estrutura as concepções teóricas que fundamentam o projeto (BARBOSA, HORN, 2008).

\section{INTERCULTURALIDADE E CURRÍCULO ESCOLAR: UM CAMPO EM DISPUTA.}

Em pesquisa nos periódicos da $\mathrm{CAPES}^{5}$, para a combinação de palavras "interculturalismo e educação" foram encontrados 47 resultados, com destaque para pesquisas nas linhas temáticas de educação indígena e imigração. Para a combinação de palavras "interculturalismo e currículo" também foi encontrada uma frequência de 47 resultados. Já para a combinação de palavras “interculturalismo e práticas escolares" foram encontrados 6 resultados. Destes, destaca-se o estudo de Canen e Oliveira (2002), por identificar as etapas de construção de uma prática curricular multiculturalista através da análise de aulas de uma professora de ciências, em uma turma do segundo segmento do Ensino Fundamental. Dessa maneira, o estudo de Canen e Oliveira (2002) se aproxima do movimento de análise aqui proposto.

O campo de estudos pós-coloniais latino-americanos (QUIJANO, 2005; 2007; MIGNOLO, 2010; 2011; GROSFOGUEL, 2008; WALSH, 2008) reivindica a produção epistêmica do conhecimento em uma perspectiva que questiona a racionalidade hegemônica produtora de uma geopolítica do conhecimento fundamentada na herança colonial (MIGNOLO, 2010). Esse conhecimento, que parte da experiência epistêmica do subalternizado, somente é concretizado a partir de uma matriz curricular educacional que se oponha ao monoculturalismo, tendo por base a interculturalidade (CANDAU, 2008).

Ampla bibliografia no campo (CANEN, 2000, 2001; CANEN E OLIVEIRA, 2002; CANDAU, 2008) aponta para a existência da polissemia em torno do termo multiculturalismo, englobando posturas conceituais conflitantes. Canen e Oliveira (2002) identificam duas linhas conceituais gerais de multiculturalismo. As autoras definem como multiculturalismo liberal ou de relações humanas a linha que defende a valorização da diversidade cultural, mas que apenas aumenta o leque de diversidade a ser apresentada, folclorizando-a, descontextualizando-a do cenário social que produz a diferença. Para as autoras, em oposição ao multiculturalismo liberal, estaria a perspectiva multicultural crítica: aquela que situa a diferença levando em consideração o contexto social produtor de desigualdades.

\footnotetext{
5 Pesquisa realizada em em 16/08/2019, às 14h16. Disponível em: <http://www-periodicos-capes-govbr.ez27.periodicos.capes.gov.br/index.php?>.
} 
Já Candau (2008) identifica três tipologias dentro do conceito de multiculturalismo: assimilacionista, diferencialista e interculturalismo. O multiculturalismo assimilacionista se insere no movimento de assimilar os grupos marginalizados à cultura hegemônica, sem perspectiva de alteração da estrutura social. Em linhas gerais, a terminologia multiculturalismo assimilacionista de Candau (2008) se aproxima conceitualmente do multiculturalismo liberal definido por Canen e Oliveira (2002).

Candau (2008) define uma segunda tipologia de multiculturalismo: o multiculturalismo diferencialista, ou monoculturalismo plural. Nessa perspectiva, a ênfase no reconhecimento da diferença garante a expressão das diferentes identidades culturais. Contudo, Candau (2008) aponta que algumas linhas da perspectiva multicultural diferencialista tendem a apresentar uma leitura estática e essencialista da formação das identidades culturais, promovendo ações de fortalecimento de grupos através de um elo de unidade, mas produzindo seu isolamento como grupo.

A terceira tipologia identificada por Candau (2008) é a o do interculturalismo. Conceito que se aproxima do de multiculturalismo crítico definido por Canen e Oliveira (2002). Para Candau (2008), a perspectiva intercultural somente é possível a partir da criação de canais de diálogo entre diferentes grupos sociais e culturais, construindo um projeto comum no campo educativo em oposição à assimetria de prestígio social desses grupos na sociedade.

Para tomar referenciais concretos para análise de construção de práticas curriculares que se aproximem de um currículo intercultural, analisaremos as práticas na/da/com a turma de Educação Infantil acompanhada a partir dos conceitos de crítica cultural (BOYLE-BAISE, GILLETTE, 1998), hibridização (MCLAREN, 2000) e ancoragem social dos discursos (GRANT, WIECZOREK, 2000).

Boyle-Baise e Gillette (1998), referem-se a crítica cultural como o processo de análise de discursos presentes na sociedade que constroem a diferença e subjugam determinados grupos. $\mathrm{O}$ momento de crítica cultural possibilita um espaço para que alunos reflitam sobre suas identidades e que interajam com as identidades uns dos outros. Já a hibridização (MCLAREN, 2000) seria um elemento fundamental para as trocas interculturais, uma vez que se caracteriza pelo cruzamento de fronteiras culturais. Já a ancoragem social dos discursos (GRANT; WIECZOREK, 2000) caracterizase pelo momento em que são estabelecidas relações entre discursos políticos, sociológicos e culturais, com a leitura das práticas sociais(CANEN; OLIVEIRA, 2002). Esses três momentos convivem de maneira circular no processo do fazer pedagógico intercultural.

A seguir apresenta-se a metodologia de desenvolvimento do projeto (BARBOSA, HORN, 2008) na/da/com a turma de Educação Infantil. 


\section{METODOLOGIA DE PESQUISA NO/DO/COM O COTIDIANO: RELAÇÕES COTIDIANAS PRODUZINDO CONHECIMENTOS.}

A pesquisa situa-se no campo de pesquisa qualitativa e a opção metodológica assumida é a de pesquisa no/do/com o cotidiano (FERRAÇO, 2007; OLIVEIRA, 2008) que se fundamenta pela indissociabilidade entre epistemologia e metodologia, numa perspectiva que toma as relações protagonizadas no cotidiano como fonte de produção de conhecimentos (OLIVEIRA, 2008). Através da observação das relações cotidianas- suas contradições, as práticas sociais que produzem/reproduzem, os grupos sociais que nela figuram e suas manifestações próprias enquanto grupo, a diversidade de matrizes epistêmicas de produção de conhecimento para além da matriz hegemônica fundamentada na herança colonial- são construídas interfaces tanto de produção de conhecimentos quanto de abertura de canais de diálogo para a intervenção sobre essa produção.

As condições para realização da pesquisa inspiram cuidados, sobretudo pela condição de liminaridade da pesquisadora como agente envolvido no fazer da ação, no caso como professora da turma. Observar fenômenos familiares, para Velho (1978), requer um exercício de relativização, de aproximação e distanciamento, tornando possível a compreensão sobre a lógica das relações dos fenômenos observados. Esse exercício de alteridade foi tomado no sentido de buscar regularidades nas relações cotidianas que se configurassem como questões de pesquisa a serem investigadas na dimensão do próprio cotidiano. Nesse sentido, pode ser considerada uma possibilidade interessante de análise a pesquisa sobre o cotidiano ser realizada por um dos, como define Ferraço (2007), “sujeitos que praticam a escola" (FERRAÇO, 2007, p 74).

Para estruturação de uma sequência didática adotou-se a concepção teórico/metodológica da Pedagogia de Projetos (BARBOSA, HORN, 2008), em uma perspectiva que se propõe a romper com a fragmentação entre conhecimento e cultura e, na qual, tanto professores quanto alunos da/na turma são co-criadores do processo de produção do conhecimento.

A seguir, apresenta-se uma breve caracterização da escola e das negociações mediadas para realização do projeto.

\section{CARACTERIZAÇÃO DO CAMPO: A ESCOLA E OS CAMINHOS POSSÍVEIS DE MEDIAÇÃO PEDAGÓGICA.}

A escola pertence a Rede Municipal de Educação do Rio de Janeiro, localiza-se em uma extensa faixa territorial de concentração de pobreza na Zona Norte do município, sendo a única escola que abarca da Educação Infantil até o $3^{\circ}$ ano do Ensino Fundamental na localidade. As demais instituições educacionais locais atendem crianças na faixa etária de 0 até 6 anos de idade, na modalidade de Educação Infantil. A turma de Educação Infantil acompanhada possui vinte e oito 
alunos, contando com um aluno com laudo de autismo. Dessa maneira, a quantidade de alunos matriculados na turma excede o limite estabelecido pela Deliberação $n^{\circ} 15$ do Conselho Municipal de Educação do Rio de Janeiro, de 29 de maio de 2007, artigo 12, item IV, que define que para cada grupo de 25 crianças, na faixa etária de 4 até 5 anos e 11 meses, em um único espaço físico, será destinado um professor ${ }^{6}$. Além do acompanhamento da docente PII $^{7}$, a turma possuía dois tempos semanais, de 50 minutos cada, de Educação Física e um tempo semanal, também de 50 minutos, de Sala de Leitura.

No ano letivo de 2017 encontravam-se no espaço da escola: quatro salas de aula, uma sala de leitura, o refeitório, a secretaria (neste espaço havia uma placa de ferro onde lia-se "Sala dos Professores", contudo o espaço era utilizado para trabalho da secretaria e da direção escolar, não sendo destinado para uso dos professores) e a área ao ar livre. O espaço ao ar livre da escola era bem reduzido e oferecia pouca segurança para as crianças atendidas. Uma pequena quadra era utilizada para as aulas de Educação Física, contudo na lateral e extremidades deste espaço havia uma elevação, o princípio de um morro de terra batida, circundado por raízes de árvores, pedras e desnivelamentos. Além do espaço externo da quadra, havia o espaço externo na lateral do refeitório com a configuração espacial de um corredor, piso de concreto irregular, com rachaduras e buracos. Esse espaço era utilizado para recreação das turmas.

Patrícia Corsino (2006) aponta que os critérios de qualidade para a oferta da Educação Infantil se estendem desde as políticas públicas para a infância até às condições físicas dos espaços e equipamentos para oferta dessa modalidade de ensino. Considerando que o espaço da instituição escolar no ano letivo de 2017 não apresentava condições que garantissem a segurança física das crianças, além da quantidade de alunos na turma estar acima do limite estabelecido pelo Conselho Municipal de Educação, constata-se comprometimento à qualidade de atendimento ao público.

A direção escolar, era composta pela diretora geral e por uma diretora adjunta, atuantes na escola desde a fundação da instituição, há 30 anos. As docentes da instituição, contudo, não apresentavam grande período de atuação na escola. No ano letivo de 2017, a docente com mais tempo na instituição contava com quatro anos de permanência na unidade. Apesar disso, majoritariamente

\footnotetext{
${ }^{6}$ A deliberação do Conselho Municipal de Educação ${ }^{\circ} 15$, de foi atualizada pela deliberação do Conselho Municipal de Educação no 30, de 3 de janeiro de 2019. A segunda apresenta no artigo 20 a distribuição da quantidade de profissionais por alunos na Educação Infantil. O item IV, do artigo 20 da deliberação no 30 está em consonância com o estipulado pela deliberação $n^{\circ} 15$.

${ }^{7}$ Refere-se a função Professor II do magistério da rede Municipal de Educação do Rio de Janeiro. Docentes PII alocados em turmas regulares cumprem a sua carga horária de trabalho semanal com a mesma turma de alunos.
} 
as docentes já apresentavam experiências na rede Municipal do Rio de Janeiro anteriores a sua atuação na escola.

Os espaços-tempos utilizados para estudos coletivos foram raros no ano letivo de 2017, considerando a própria estrutura definida pelo calendário letivo da Rede Municipal de Educação do Rio de Janeiro. Os momentos de planejamento individual das docentes que permaneciam mais tempo com a turma (professoras função PII e PEI ${ }^{8}$ ) também eram comprometidos. Uma vez que, os tempos de planejamento dessas docentes estavam vinculados ao tempo de aula dos docentes PI (docentes das disciplinas de Inglês, Artes, Educação Física e docente alocado na sala de leitura). Uma outra dificuldade também encontrada para a realização do planejamento foi a ausência de espaço para sala de professores. Os professores poderiam utilizar o espaço da sala de leitura para planejamento, contudo este espaço possuía dimensão física extremamente reduzida, abrigando mesas com computadores, estantes, máquina de xerox e cadeiras, além de nele ser oferecido atendimento aos alunos.

$\mathrm{Na}$ construção das relações cotidianas da escola o fazer pedagógico aproximava-se da concepção teórico-metodológica da pedagogia transmissiva (FORMOSINHO, 2007), numa perspectiva em que os alunos são seres a espera de participação, sem voz ativa no processo. Em relação a Educação Infantil, as falas da gestão em Conselhos de Classe apontaram para uma expectativa de início ou preparação do processo de alfabetização formal dos alunos. Nesse sentido, a gestão escolar sugeriu em fala no $1^{\circ}$ Conselho de Classe que as atividades ministradas na turma de Educação Infantil, com crianças na faixa etária de 5 anos, fossem prioritariamente as de linguagem escrita, em que os alunos repetissem o traçado de letras e números para que não chegassem "zerados" (expressão utilizada pela diretora geral) no $1^{\circ}$ ano. Nunes (2006) opõe-se a essa concepção de Educação Infantil como etapa preparatória para o Ensino Fundamental e aponta a potencialidade dessa modalidade de ensino como espaço de formação cultural. A sugestão da gestão de priorizar nessa modalidade de ensino a repetição de traçados de números e letras denota não apenas a concepção de Educação Infantil como uma etapa preparatória para o Ensino Fundamental, mas a própria ausência da construção de significados no processo de aquisição e desenvolvimento da linguagem escrita, para além da ausência de intervenção do aluno a partir de seus referenciais culturais no processo de produção do conhecimento.

Dessa maneira, considerando a concepção sobre Educação Infantil que vigora na escola, houveram tensões para realização do projeto na/da/com a turma. Foi preciso buscar formas de abordar

\footnotetext{
${ }^{8}$ A designação PEI refere-se à função Professor de Educação Infantil da rede Municipal de Educação do Rio de Janeiro.
} 
o tema que se inserissem nas rotinas de fazeres cotidianos mais regulares. Nesse sentido, uma linha de fuga possível foi inserir a temática nas rodas de leitura semanais. Para isso, buscou-se uma seleção de títulos literários que se relacionassem com as principais questões presentes nas falas das crianças que denotavam estereótipos raciais. Considerando que os cabelos crespos e a cor da pele foram muito manifestos, buscou-se iniciar os caminhos de pesquisa por essas temáticas.

A seguir apresentam-se as práticas analisadas que se aproximariam da perspectiva interculturalista (CANDAU, 2008) em relação à matriz curricular da educação para as relações étnico-raciais.

\section{CURRÍCULO E INTERCULTURALIDADE NA EDUCAÇÃO INFANTIL: A PRODUÇÃO DA DIFERENÇA COMO PRÁTICA SOCIAL NA MATRIZ CURRICULAR DAS RELAÇÕES ÉTNICO RACIAIS.}

As atividades realizadas ocorreram entre os meses de maio a dezembro de 2017. As rodas de leitura ocorreram semanalmente, contudo as atividades propostas intercalaram-se em espaços maiores de tempo, considerando que algumas atividades exigiram um período maior de desenvolvimento. Para fins didáticos, segmentam-se as atividades realizadas em três grandes subitens: rodas de leitura, as atividades entre pares e atividades realizadas juntamente com os responsáveis dos alunos. Ressaltase que aqui foram selecionadas algumas atividades do projeto, portanto não será apresentada a totalidade de produções da turma ao longo deste.

5.1- Rodas de leitura: a elaboração oral como ferramenta de reelaboração do pensamento.

A roda de leitura consiste em um momento coletivo em que os alunos têm contato com leituras de histórias e interagem a partir de seus elementos, colocando impressões e fazendo relações com outros acontecimentos de suas vidas. A partir daí surgem interesses de investigação que constroem os próximos passos do projeto.

O texto literário foi adotado enquanto produção artística, tendo como intuito primordial a apreciação da produção literária. Por outro lado, a escolha dos títulos orientou-se tanto pela qualidade da narrativa quanto pelo protagonismo de personagens negros dentro destas, com vistas a apresentar referenciais aos alunos que se diferenciassem do referencial de branquitude. Cordeiro ressalta o protagonismo da literatura infantil nesse sentido:

A literatura infanto-juvenil possui um papel basilar para auxiliar os leitores a reconhecerem a existência de uma sociedade heterogênea, e passarem, então, a valorizarem tanto a sua cultura quanto a dos outros indivíduos (CORDEIRO, 2011, p. 92). 
A tabela 1 apresenta os títulos dos livros selecionados para as rodas de leitura.

\begin{tabular}{|c|c|c|}
\hline Títulos Selecionados. & Autores. & Ano. \\
\hline Matl Cabeios de Ritinha. & $\begin{array}{l}\text { Paloma Monteiro e Daniel } \\
\text { Gnattalli. }\end{array}$ & 2013 \\
\hline $\begin{array}{l}\text { Kalinda a Princesa que } \\
\text { perdeu or Cabejos. }\end{array}$ & Celso Sisto. & 2016 \\
\hline $\begin{array}{l}\text { Menina Bonita do Laço de } \\
\text { Fita. }\end{array}$ & Ana Maria Machado. & 2005 \\
\hline Crico Juba. & Gustavo Gaivota. & 2016 \\
\hline As tramsas de Bintoli. & Sylviane Anna Diouf & 2004 \\
\hline Nato Derrame o Leite. & Stephen Davies. & 2015 \\
\hline Chuva de Manga & Tames Rumford. & 2011 \\
\hline $\begin{array}{l}\text { Oranyam } \text { e } \\
\text { Pescaria. }\end{array}$ & \begin{tabular}{|l} 
Dayse Moura. \\
\end{tabular} & 2014 \\
\hline Brwna ef a Galinha D'angoia & Gercilga de Almeida. & 2011 \\
\hline A Históría do Rei Gaianga & Geranilde Costa. & 2011 \\
\hline $\begin{array}{l}\text { Omo-oba: histórias de } \\
\text { princesas. }\end{array}$ & Riugam de Oliveira. & 2009 \\
\hline$O \operatorname{san} x$ & Ancire Neves. & 2010 \\
\hline Alíce vé. & Sónia Rosa. & 2014 \\
\hline$O$ menino Nito. & Sónia Rosa. & 2006. \\
\hline $\begin{array}{l}\text { Paienmo e Neneco: wh atia na } \\
\text { aldeía Mbya-Guarani. }\end{array}$ & Ana Carvalho. & 2014 \\
\hline $\begin{array}{l}\text { A História de Akuḱusia - } O \\
\text { Dono da Caça. }\end{array}$ & Rita Carelli. & 2014 \\
\hline No Tempo do Verdo. & Mariana Zanetti. & 2014 \\
\hline $\begin{array}{l}\text { Das Criancas Ikpeng para o } \\
\text { Mundo. }\end{array}$ & Rita Carelli & 2015 \\
\hline Depois do Ovo a Guerra. & Ana Carvalho. & 2015 \\
\hline $\begin{array}{l}\text { A Historia do Monstro } \\
\text { Khâtpy. }\end{array}$ & Mariana Zanetti. & 2015 \\
\hline
\end{tabular}

Os primeiros livros trazidos para roda articulavam-se com as falas dos alunos que valorizavam o fenótipo branco e reproduziam estereótipos aos fenótipos negros. Na roda a partir do livro "Mil cabelos de Ritinha", ainda que o texto literário não apresente a palavra "cachos", a aluna Carol reelabora a história e se utiliza do termo "cacheado" para definir o cabelo de Ritinha: "Ela tem o cabelo cacheado e usa um monte de penteados." (Carol). Carol começa a realizar constatações de quem na sala tem os cabelos cacheados e se inclui nessa observação. Laila, uma das alunas identificadas por Carol como pertencente ao grupo de cabelos cacheados diz: "O meu não é cacheado não." Carol argumenta: "É sim”. Laila responde: "É liso aqui na frente e só cacheia na ponta" (faz referência ao seu próprio cabelo preso). Nesse bloco inicial dos debates foram manifestas contradições entre o fenótipo que a criança apresentava e o fenótipo que esta imaginava apresentar, como no caso narrado de Laila que, de fato, possui cabelos crespos. Essa contradição também aparece na atividade entre pares na produção de autorretrato.

Um segundo momento da seleção de histórias contou com textos literários que incluíam elementos da paisagem natural da Nigéria (menções ao Rio Níger em “Oranyam e a grande pescaria” 
e "Não derrame o leite") e do Xade (onde se passa a narrativa de "Chuva de Manga"). Contudo, o elemento que mais chamou atenção das crianças tanto nos textos de "Não derrame o leite" como em "Chuva de manga" foi a manga. A partir desse interesse, foram desenvolvidas atividades entre pares $\mathrm{da} / \mathrm{na} / \mathrm{com}$ a turma sobre a fruta.

Figura 1 - Contação de história com bonecos de garrafa.

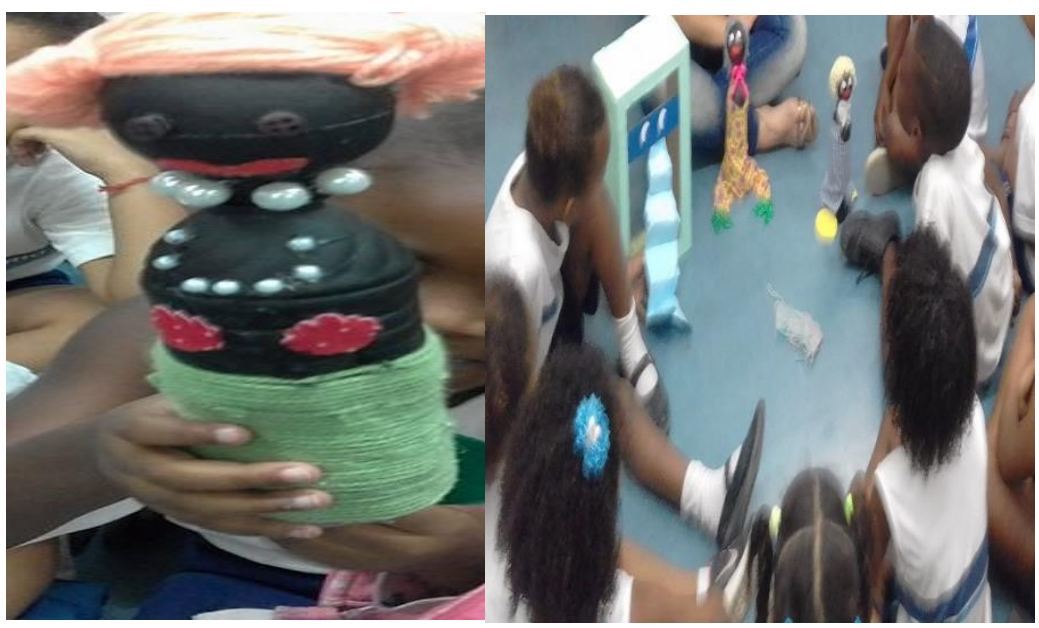

Fonte: A autora, 2017.

Figura 2 - Produção artística personagem Ritinha.

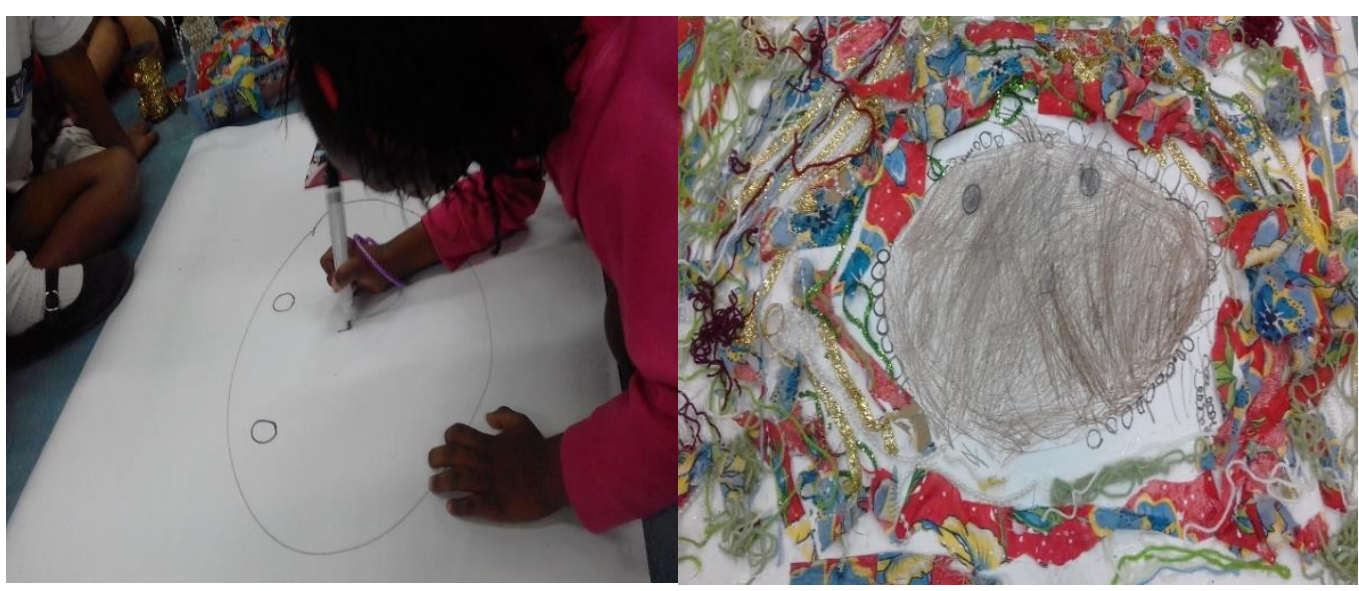

Fonte: A autora, 2017.

O terceiro grupamento de livros selecionados contou com textos literários com personagens negros como protagonistas, em narrativas cotidianas nas quais seu pertencimento racial não é enfatizado. A inclusão desse grupamento foi considerada importante no sentido de trazer narrativas para o universo infantil com referenciais raciais distintos dos da branquitude. O quarto e quinto grupamentos de livros selecionados contam com histórias de reis, rainhas, príncipes e princesas negros e histórias com crianças indígenas como protagonistas, respectivamente. Nos dias das rodas 
de leitura, que ocorriam às sextas-feiras, as crianças puderam fazer empréstimos de livros na sala de leitura da escola. Como, majoritariamente, os livros lidos nas rodas de leitura fizeram parte do acervo pessoal da docente, estes também foram disponibilizados para empréstimo.

A partir dos interesses da turma elaborados durante as rodas de leitura, foram propostas atividades entre pares na/da/com a turma. Estas serão apresentadas no tópico a seguir.

\section{2- ATIVIDADES ENTRE PARES.}

As atividades sobre representação do corpo contaram com produção de autorretrato e produção de uma representação de si a partir do desenho da sombra de cada criança. A atividade de autorretrato foi realizada de maneira coletiva, inserida nas atividades diversificadas ${ }^{9}$, em esquema de rodízio. Assim, foram dispostas folhas A4, lápis de cor e pequenos espelhos colocados em uma das mesas da sala. A proposta consistia em realizar e colorir um desenho de si mesmo com auxílio da observação de seu próprio reflexo no espelho. Nessa atividade ficou muito marcada a contradição entre algumas representações gráficas e o fenótipo da criança autora da representação. Luiz, ao se olhar no espelho afirmou: "O meu olho é verde" (definindo o aluno por hetero-classificação ${ }^{10}$, Luiz tem os olhos pretos e possui coloração de pele pouco retinta). Carol também apresentou essa contradição tanto na elaboração oral sobre si quanto na representação gráfica. Contudo, nenhuma criança branca se representou como negra nos autorretratos.

Figura 3 - Produção de autorretrato.

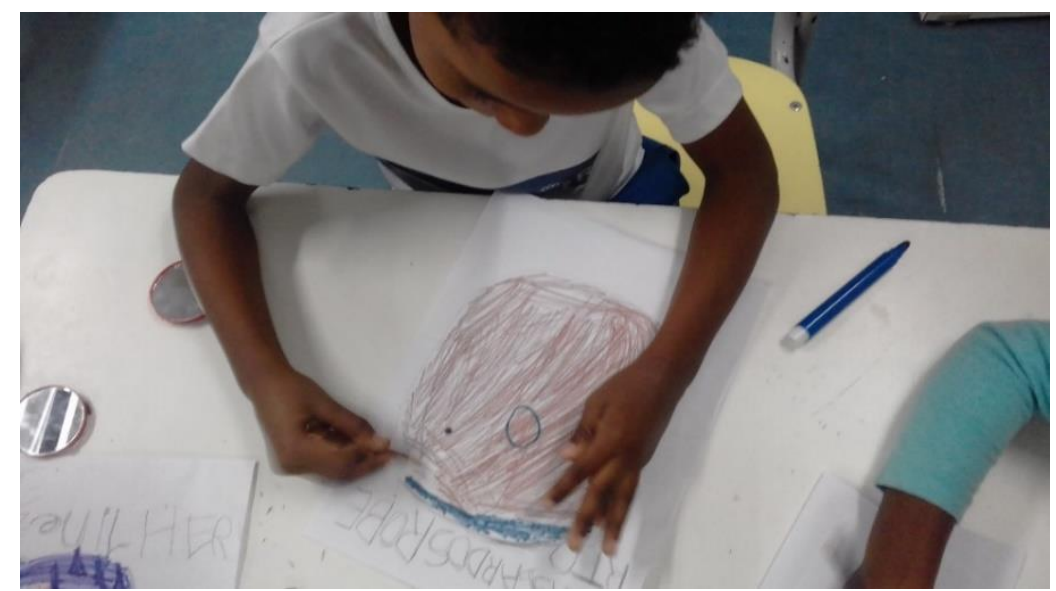

\footnotetext{
${ }^{9}$ As atividades de rodízio caracterizam-se por uma disposição de atividades diversificadas em sala de aula nas quais os alunos da turma circulam pelas atividades.

${ }^{10} \mathrm{O}$ termo refere-se à classificação de cor atribuída ao sujeito por outrem, não sendo definida por ele próprio. Em levantamentos censitários para caracterização populacional promovidos pelo IBGE adota-se a autoclassificação, em que o indivíduo declara sua cor.
} 
Fonte: A autora, 2017.

Em parceria com o professor de Educação Física foram realizadas atividade de desenho a partir da sombra dos alunos. Em duplas ou em trios os alunos se posicionavam contra o sol a fim de projetar sua sombra na cartolina colada no chão, outros colegas da turma realizavam o desenho da sombra. Posteriormente, os alunos escreveram nessas produções (foi respeitada a hipótese sobre a linguagem escrita em que se encontravam, sendo anexados aos desenhos a tradução para escrita ortográfica ao lado de seus textos) suas características físicas e pessoais, produzindo uma outra produção de auto identificação mais abrangente do que a do autorretrato. Nessa segunda produção de auto identificação foram mais manifestas descrições que se aproximam de fenótipos não brancos, como "cabelos cacheados", "trancinha no cabelo", "pele pretinha" e "pele morena" (expressões utilizadas pelos alunos). Apesar de ainda ocorrerem falas das crianças com reprodução ao referencial estético de branquitude (que pode ser identificado pela utilização dos termos "pele pretinha" e "pele morena" como suavizações do fenótipo negro e aproximação deste com o referencial da branquitude), foi possível perceber algumas alterações gradativas em relação a forma como os alunos percebiam a estética física da população negra e como passaram a incorporá-las em auto representações. Dessa maneira, pode-se inferir uma aproximação ao conceito de crítica cultural de Grant e Wieczorek (2000).

Figura 4 - Desenho em sombra - Atividade integrada com professor de Educação Física

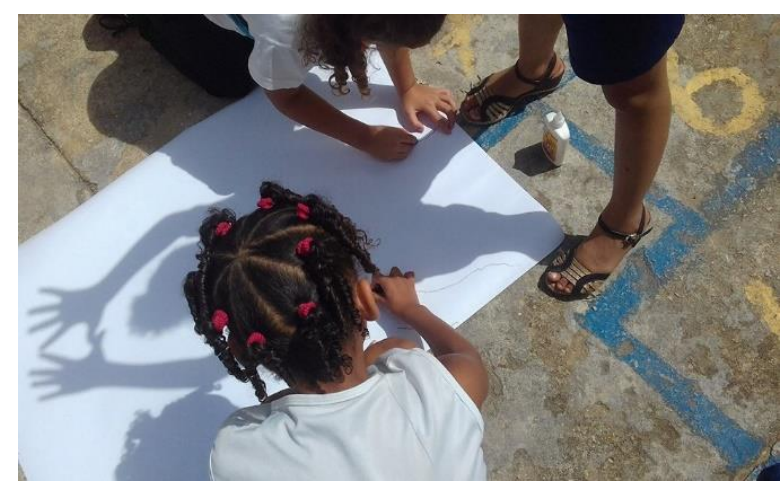

Fonte: A autora, 2017.

Também integraram as atividades entre pares um grande bloco de produções sobre a fruta manga que emerge como um interesse de pesquisa da turma a partir das rodas de leitura. Inicialmente, a proposta foi de observação da fruta. Para investigar a manga os alunos confeccionaram lunetas com rolos de papel toalha e papel higiênico. Após a pintura e secagem das lunetas, as crianças observaram uma manga espada e uma manga rosa. Foram fomentados pela docente questionamentos sobre diferenças entre as mangas. A primeira constatação da turma foi que a manga era geladinha (estavam na geladeira antes de serem levadas à sala de aula), então passaram a descrever a manga em cores, 
peso, tamanho e características de sua polpa. Como combinado coletivo, elaborou-se a proposta de pesquisa de informações sobre a origem da fruta como tarefa de casa. Durante a atividade de investigação, a própria turma aponta a manga como fonte de alimento e sugere a produção de sacolés de manga.

Figura 5: Investigação dos diferentes tipos de manga e produção coletiva de sacolés de

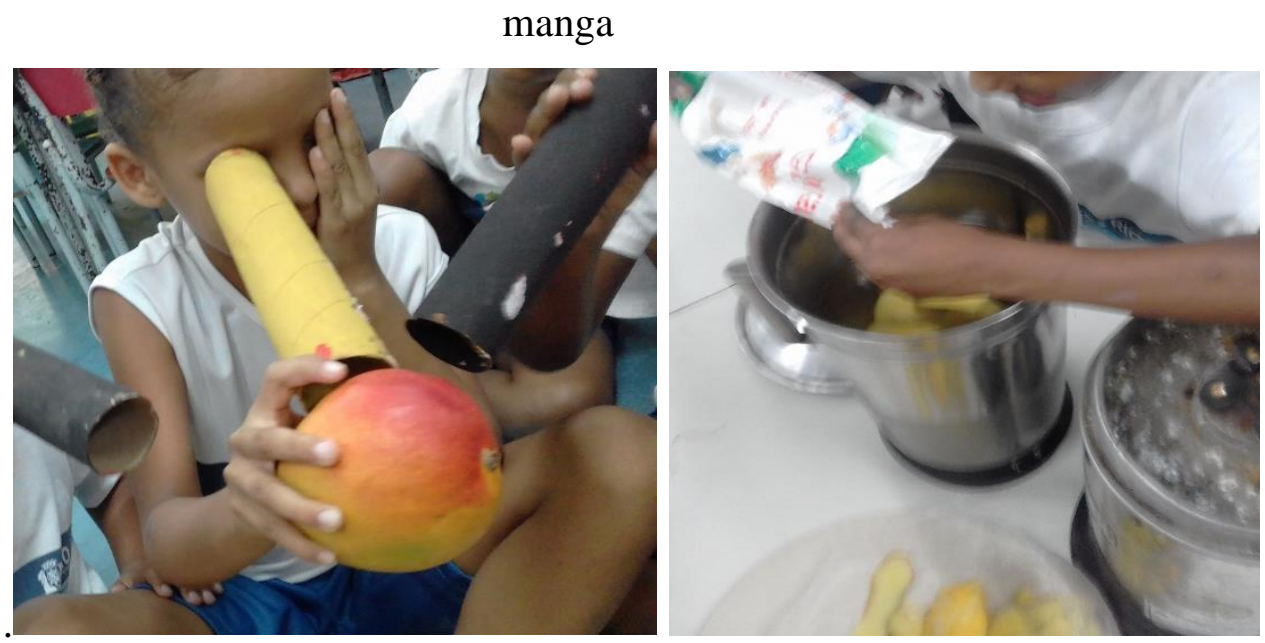

Fonte: A autora, 2017.

Dentre as demais atividades entre pares na/da/com a turma, destacou-se a confecção das bonecas abayomi. Essa atividade também ocorreu dentro da dinâmica de atividades diversificadas em esquema de rodízio. O modelo de boneca abayomi construído foi o confeccionado com cinco nós. Foi utilizado tecido colorido para confecção das bonecas, além de tesouras para pequenos arremates. A roda de leitura do dia contou com a contação de história sobre a abayomi, destacando que a origem da palavra possui gênero neutro, podendo ser usada tanto para masculino quanto para feminino na tradução para o português. Um dos alunos, Nicholas, diz que o boneco dele é um samurai (a vestimenta da abayomi lembra um vestido ou um kimono samurai). Ana diz: "O meu é cachorro" (sua abayomi ficou com uma das tiras fora do nó, lembrando uma terceira perna ou um rabo de animal). Esse momento de produções entre pares se aproxima do conceito de hibridização de McLaren (2000), uma vez que houve o cruzamento de fronteiras entre culturas distintas.

$\mathrm{Na}$ sequência do texto, descreveremos as atividades realizadas em integração com responsáveis da turma e com outros profissionais da unidade escolar. 


\section{3- ATIVIDADES EM INTEGRAÇÃO COM RESPONSÁVEIS DE ALUNOS.}

Os responsáveis de alunos da turma mantiveram parceria ao longo de todo o desenvolvimento do projeto, desde a realização dos trabalhos escolares para casa (ainda que com adesão parcial da realização destes) até a devolução e conservação dos empréstimos de livros. Na terceira reunião com responsáveis do ano letivo de 2017, realizada em agosto, foi proposta uma roda de conversa com responsáveis e alunos. Após uma conversa inicial sobre como se desenvolveram as tarefas de casa integrantes do projeto, a docente questionou alunos e responsáveis presentes sobre quem e como eram os príncipes e princesas das histórias clássicas. Aparece o fenótipo mais manifesto de mulheres de pele clara e cabelos lisos. A partir disso, foram apresentadas imagens das famílias reais de Lesoto, Suazilândia, e da tribo Mende de Serra Leoa. Além de serem famílias compostas por pessoas negras, as famílias reais desses locais têm membros que fogem ao estereótipo físico ligado a magreza que é valorizado pela cultura ocidental. A turma recontou a história "A História do Rei Galanga", de Geranilde Costa, na roda de conversa com os responsáveis. Um dos alunos pediu para mostrar a boneca Kalinda (personagem de um dos contos presentes no livro "Kalinda a Princesa que perdeu os Cabelos”, de Celso Sisto) para sua avó que estava presente na roda. Após essa discussão, foi proposto que cada responsável confeccionasse junto à criança um príncipe ou princesa a seu modo. Nessa atividade foram utilizados papéis crepom, botões, miçangas, fitas e fitilhos coloridos, retalhos de chita, tesoura e cola.

Figura 6- Oficina "Príncipes e Princesas" na $3^{\circ}$ Reunião com Responsáveis.

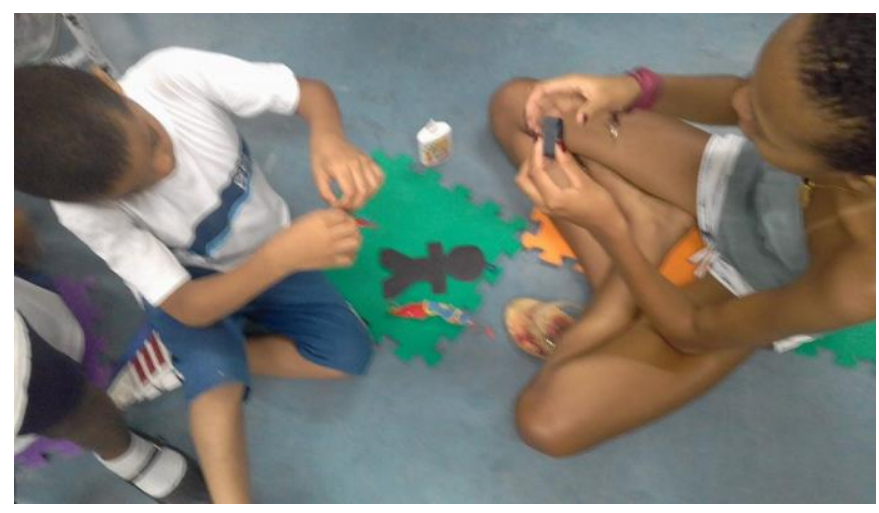

Fonte: A autora, 2017.

O projeto também contou com uma apresentação para toda a escola: o desfile de turbantes e apresentação da história das bonecas abayomi durante o evento comemorativo da Festa da Primavera. Como dito anteriormente, a unidade escolar orienta seu currículo pelos marcos temporais de datas comemorativas. A apresentação de um dos resultados do projeto da turma nesse evento foi uma linha de fuga possível para que a turma integrasse uma atividade coletiva escolar através de trabalho próprio 
desenvolvido. Essa atividade também contou com apoio das famílias dos alunos. Foi solicitado que as alunas levassem para escola meia calça ou calça legging para confecção dos turbantes. O desfile de turbantes ocorreu junto à apresentação oral e exposição das bonecas abayomi.

\section{RESULTADOS.}

É preciso, antes de tudo, indicar que os resultados do projeto são parciais na medida em que a construção de um currículo intercultural não se configura em um período delimitado espaçotemporalmente, mas se faz ao longo do processo de formação no fomento de vivências que questionem matrizes culturais tão "naturalizadas". Faz-se necessário, ainda, uma ponderação entre as concepções pedagógicas distintas entre os fazeres cotidianos da/na instituição, de maneira geral, que se aproximam da concepção teórico-metodológica da pedagogia transmissiva (FORMOSINHO, 2007) e um projeto que se propõe a construção de práticas intraescolares que se aproximem da interculturalidade. Esse contexto propôs desafios ao projeto e, em alguma medida, limitou as possibilidades de ampliação de parcerias dentro da instituição para o mesmo.

Os resultados do projeto apontam para a necessidade de ampliação e análise das formas de implementação da lei 11.645/2008 que dispõe sobre a obrigatoriedade do ensino da História e Cultura Africana e Afrobrasileira e culturas de etnias indígenas, uma vez que ainda se verifica o tratamento do tema como um apêndice curricular circunscrito em períodos específicos de celebração de datas comemorativas.

Os resultados ainda indicam a relação dos conceitos de hibridização de McLaren (2000) e de crítica cultural de Boyle-Basse e Gilete (1998) como elementos potencializadores de construção de um currículo que se aproxime de práticas interculturais. Ao longo da sequência de atividades realizadas na/da/com a turma foi possível identificar o percurso dos discursos dos alunos desde a crítica cultural (BOYLE-BASSE; GILETE, 1998) com a reflexão sobre percepções estereotipadas sobre traços físicos característicos da população negra, até a hibridização (MCLAREN, 2000) em que são reconhecidos traços de outra matriz cultural sem estereotipá-la e uma aproximação ao conceito de ancoragem social dos discursos de Grant e Wieczorek (2000), na medida em que foi possível perceber algumas alterações gradativas em relação a forma como os alunos percebiam a estética física da população negra e como passaram a incorporá-las em auto representações.

Para não concluir, faz-se necessário salientar a importância do trabalho pedagógico de construção de um currículo com práticas intraescolares que se aproximem da interculturalidade, sobretudo, em um contexto político nacional de instabilidade frente aos valores da democracia e de invisibilidade da diversidade. O fazer pedagógico se traja de significado frente aos seus partícipes na 
medida em que é socio referenciado. Somente dessa maneira é possível a produção da educação na/da/pela/para diversidade.

\section{REFERÊNCIAS.}

BARBOSA, M. C.; HORN, M. G. S. Projetos Pedagógicos Na Educação Infantil. Porto Alegre: Artmed, 2008. 128p. BOYLE-BAISE, M.; GILLETTE, M. Multicultural education from a pedagogical perspective: a response to radical critiques. Interchange, v. $29, \quad$ n. $1, \quad$ p. $17-32, \quad 1998 . \quad$ Disponível em: <https://link.springer.com/article/10.1023\%2FA\%3A1007444303156>. Acesso em: 15 agost. 2018.

BRASIL. Lei 9.394/96, de 0 de dezembro de 1996. Lei de Diretrizes e bases da Educação Nacional. Diário Oficial da União, Poder Executivo, Brasília, DF, 1996.

BRASIL. Ministério da Educação e do Desporto. Lei 10.639/2003, de 9 de janeiro de 2003. Altera a Lei nº 9. 394, de 20 de dezembro de 1996. Diário Oficial da União, Poder Executivo, Brasília, DF, 2003.

BRASIL. Ministério da Educação e do Desporto. Lei 11.645/08 de 10 de Março de 2008. Diário Oficial da União, Poder Executivo, Brasília, DF, 2008.

BRASIL. Ministério da Educação e do Desporto. Lei 13.415/2017, de 16 de fevereiro de 2017. Altera a Lei nº 9.394 , de 20 de dezembro de 1996. Diário Oficial da União, Poder Executivo, Brasília, DF, 2017.

BRASIL. Ministério de Educação e do Desporto. Referencial Curricular Nacional para Educação Infantil. Diário Oficial da União, Poder Executivo, Brasília, DF: MEC, 1998.

BRASIL. Ministério da Educação. Plano Nacional de Implementação das Diretrizes Curriculares Nacionais da Educação das Relações Étnico-Raciais e para o Ensino de História e Cultura Afro-brasileira e Africana. Brasília, DF: SECAD, Novembro de 2009.

CANDAU, V. M. Direitos Humanos, educação e interculturalidade: as tensões entre igualdade e diferença. Revista Brasileira de Educação, v. 13, n. 37, p. 45-46, jan./abr. 2008 . Disponível em: <http://www.scielo.br/pdf/rbedu/v13n37/05.pdf>. Acesso em: Acesso em: 19. agost. 2018.

CANEN, A. Educação multicultural, identidade nacional e pluralidade cultural; tensões e implicações curriculares. Cadernos de Pesquisa, n. 111, p. 135-150, 2000. Disponível em: <http://www.scielo.br/scielo.php?pid=S010015742000000300007\&script=sci_abstract\&tlng=pt $>$.

Acesso em: 19. agost. 2018.

Universos culturais e representações docentes: subsídios para formação de professores para a diversidade cultural. Educação e Sociedade, n. 77, p. 207-227, 2001. Disponível em: < http://www.scielo.br/scielo.php?pid=S0101-73302001000400010\&script=sci_abstract\&tlng=pt $>$. Acesso em: 19. agost. 2018.

CANEN, A.; OLIVEIRA, A. M. A. Multiculturalismo e currículo em ação: um estudo de caso. Revista Brasileira de

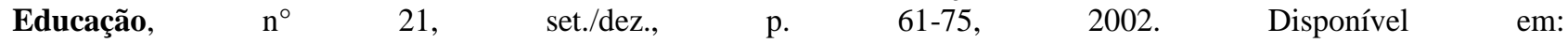
<http://www.scielo.br/scielo.php?script=sci_arttext\&pid=S1413-24782002000300006>. Acesso em: 19. agost. 2018.

CORDEIRO, M. B. S. A literatura infantojuvenil e a identidade étnica: representações do negro em O cabelo de Lelê. DLCV, João Pessoa, v. 8, n. 2, jul./dez. 2011. Disponível em: < http://www.periodicos.ufpb.br/ojs/index.php/dclv/article/viewFile/10787/7071 >. Acesso em: 19. Agost. 2018.

CORSINO, P. O Cotidiano na Educação Infantil. Salto para o Futuro. O cotidiano na Educação Infantil. Ministério da Educação. Secretaria de Educação à Distância. Boletim 23, novembro 2006. Disponível em: <http://www.escolasapereira.com.br/arquivos/175810Cotidiano.pdf>. Acesso em: 19. agost. 2018.

RIO DE JANEIRO. Conselho Municipal de Educação. Deliberação E/CME nº30, de 03 de janeiro de 2019. Rio de Janeiro: Diário Oficial Municipal do Rio de Janeiro. Disponível em : <http://www.rio.rj.gov.br/dlstatic/10112/9129515/4229701/DeliberacaoCMEn30publ.pdf>. Acesso em: 19 agost. 2018. 
RIO DE JANEIRO. Conselho Municipal de Educação. Deliberação E/CME nº15, de 29 de maio de 2007. Rio de Janeiro: Diário Oficial Municipal do Rio de Janeiro. Disponível em: <http://www.rio.rj.gov.br/dlstatic/10112/1122564/DLFE-205670.pdf/deliberacao15_2.pdf>. Acesso em: 19 agost. 2019.

FERRAÇO, C. E. Pesquisa com o cotidiano. Educação e Sociedade, Campinas, v. 28, n. 98, p 73-95, jan/abril, 2007. Disponível em: 〈http://www.scielo.br/pdf/es/v28n98/a05v2898.pdf>. Acesso em: 20 agost. 2018.

FORMOSINHO, J. O.; KISHIMOTO, T. M.; PINAZZA, M. A. (orgs). Pedagogia(s) da Infância: dialogando com o passado, construindo o futuro. Porto Alegre: ARTMED, 2007. 328p.

GROSFOGUEL, R. Para descolonizar os estudos de economia política e os estudos pós-coloniais: transmodernidade, pensamento de fronteira e colonialidade global. Revista Crítica de Ciências Sociais, n. 80, p. 115-147, 2008. Disponível em: 〈https://journals.openedition.org/rccs/697>. Acesso em: 08 agost. 2019.

GRANT, C. A. WIECZOREK, K. Teacher education and knowledge in the "knowledge society"; the need for social moorings in our multicultural schools. Teachers College Record, v. 102, n. 5, p. 913-935, 2000. Disponível em: <https://eric.ed.gov/?id=EJ617137>. Acesso em: 19. agost. 2018.

MCLAREN, P. Multiculturalismo revolucionário: pedagogia do dissenso para o novo milênio. Porto Alegre: Artes Médicas, 2000. 304p.

MIGNOLO, W. Desobediencia epistémica: retórica de la modernidad, lógica de la colonialidad y gramática de la descolonialidad. Argentina: Ediciones del signo, 2010. 128p

Historias locales/diseños globales: Colonialidad, conocimientos subalternos y pensamiento fronterizo. $1^{\mathrm{a}}$ reimpresión. Madrid: Akal, 2011. 452p.

NUNES, M. F. R. Educação Infantil: instituições, funções e propostas. Salto para o Futuro. O cotidiano na Educação Infantil. Ministério da Educação. Secretaria de Educação à Distância. Boletim 23, novembro 2006. Disponível em: <http://www.escolasapereira.com.br/arquivos/175810Cotidiano.pdf>. Acesso em: 19. agost. 2018.

OLIVEIRA, I. B. Estudos do cotidiano, pesquisa em educação e vida cotidiana: os desafios da coerência. ETD- Educação Temática Digital. Campinas, $\mathrm{v}$ 9, $\mathrm{n}$ esp, $\mathrm{p}$ 162- 184, out 2008. Disponível em: <https://periodicos.sbu.unicamp.br/ojs/index.php/etd/article/view/1050/1065>. Acesso em: 19 . agost. 2018

QUIJANO, A. Colonialidade do poder, eurocentrismo e América Latina. A colonialidade do saber: eurocentrismo e ciências sociais. LANDER, E. (Org.)3. ed. Buenos Aires: CLACSO, 2005, p. 227-278. 278p.

. Colonialidad del poder y clasificación social. El giro decolonial: Reflexiones para una diversidad epistémica más allá del capitalismo global. CASTRO-GÓMEZ, S.; GROSFOGUEL, R. (Org.). Bogotá: Siglo del Hombre Editores; Universidad Central, Instituto de Estudios Sociales Contemporáneos y Pontificia Universidad Javeriana, Instituto Pensar, 2007, p. 93-126. 223p.

VELHO, G. Observando o familiar. Individualismo e cultura: notas para uma antropologia da sociedade contemporânea. Rio de Janeiro: Jorge Zahar, 1978. 149p.

O desafio da proximidade. Pesquisas Urbanas: Desafios do trabalho antropológico. VELHO, Gilberto \& KUSCHNIR, Karina. Rio de Janeiro, Jorge Zahar Ed., 2003. p. 11-19. 236p.

WALSH, C. Interculturalidad, plurinacionalidad y decolonialidad: Las insurgencias político-epistémicas de refundar el Estado. Tabula Rasa. Bogotá - Colombia, №.9, p. 131-152: julio-diciembre 2008. Disponível em: <http://www.scielo.org.co/pdf/tara/n9/n9a09.pdf>. Acesso em: 20. agost.2018. 
Interculturalidade na Educação Infantil: a matriz curricular das relações étnico-raciais.

Resumo: A pesquisa analisa a relação entre interculturalismo (CANDAU, 2008) e currículo escolar em uma turma de Educação Infantil, com crianças na faixa etária de 5 anos, em uma escola da Rede Municipal de Educação do Rio de Janeiro. Tem por objetivo analisar atividades desenvolvidas na turma que se aproximem de práticas curriculares interculturais no que tange a educação para as relações étnico-raciais. Trata-se de pesquisa qualitativa, com metodologia de pesquisa no/do/com o cotidiano. Os resultados apontam para a necessidade de ampliação e análise das formas de implementação da lei 11.645/2008 na Educação Básica, uma vez que na escola acompanhada o tema parece ser tratado como um apêndice curricular delimitado por marcos temporais de datas comemorativas.

Palavras chave: interculturalidade, Educação Infantil, relações étnico-raciais.

Interculturality in Early Childhood Education: the curriculum matrix of ethnic-racial relations.

Abstract: The research analyzes the relations between interculturalism (CANDAU, 2008) and school curriculum in one Early Childhood Education, with children aged 5 years, in a school of Rio de Janeiro Municipal public education. Its objective is to analyse activities developed in the class that are close to intercultural curricular practices regarding education for ethnic-racial relations. It is a qualitative research, with research methodology in/with/from daily life. The results point to the need for expansion and analysis of the ways to implementing the law 11.645/2008 in elementary education, since in the accompanied school the theme seems to be treated as a curricular appendix delimited by commemorative celebrations.

Keywords: interculturality, Early Childhood Education, ethnic-racial relations.

Interculturalidad en la educación de la primera infancia: la matriz curricular de las relaciones étnico-raciales.

Resumen: La investigación analisa la relación entre la interculturalidad (CANDAU, 2008) y el currículo escolar em uma classe de la primera infancia, con ninõs de 5 años, en una escuela de la Red de Educación Municipal do Rio de Janeiro. Su objetivo es analizar las actividades desarroladas en la clase que están cerca de las prácticas curriculares interculturales relacionadas con la educación para las relaciones étnico-raciales. En una investigación cualitativa, con metodología de investigación en/con/desde la vida diaria. Los resultados apuntam a la necessidad de ampliar y analizar las formas de implementar la Ley 11.655/2008 en Educación Básica, ya que en la escuela acompanãda el tema parece tratarse como un apéndice curricular delimitado por fechas conmemorativ.

Palabras clave: interculturalidad, educación de la primera infancia, relacionas étnico-raciales.

Submetido em Agosto de 2019

Aprovado em Dezembro de 2019 